\title{
O LOCAL E ALÉM: AS POÉTICAS EM TRÂNSITO DE PAULA TAVARES E CONCEIÇÃO LIMA
}

THE LOCAL AND BEYOND:

THE POETICS IN TRANSIT OF PAULA TAVARES AND CONCEIÇÃO LIMA

Bernardo Nascimento Amorim

Pós-doutor do Programa de Pós-Graduação em Estudos Literários da Universidade Federal de Minas Gerais (UFMG). 
Resumo: 0 artigo apresenta apontamentos acerca de traços característicos das poéticas de Paula Tavares e Conceição Lima, com referências aos dois primeiros livros da angolana, Ritos de passagem (1985) e O lago da lua (1999), e ao segundo e ao terceiro da são-tomense, $A$ dolorosa raiz do micondó (2006) e $O$ país de Akendenguê (2011). Procuro pensar sobre como tais poetas lidam com a herança que seus predecessores lhes legaram, demonstrando de que forma, consciente e propositalmente conectadas com determinados lugares, ambas fazem também o elogio da travessia, constituindo-se como exemplares de uma postura avessa a qualquer monolitismo.

Palavras-chave: Paula Tavares, Conceição Lima, lugar de origem, travessia. 
Abstract: The paper presents notes concerning characteristic features of Paula Tavares and Conceição Lima's poetics, with references to the first two books of the Angolan, Ritos de passagem (1985) and O lago da lua (1999), and to the second and third of the São Toméan, $A$ dolorosa raiz do micondó (2006) and $O$ país de Akendenguê (2011). I try to think about how these poets deal with the inheritance their predecessors have bequeathed to them, demonstrating how, consciously and purposely connected with certain places, both also praise the crossing, making themselves as exemplars of a posture that is contrary to any monolithism.

Keywords: Paula Tavares, Conceição Lima, place of origin, crossing. 


\section{Introdução}

Poetas contemporâneas, ambas tendo começado a publicar seus livros após a independência de seus países de origem, Angola e São Tomé e Príncipe, respectivamente, Paula Tavares e Conceição Lima têm se destacado, já há algum tempo, no cenário das letras dos países africanos de língua oficial portuguesa que conseguem ultrapassar as fronteiras de África. No Brasil, Tavares é uma das pouquíssimas autoras africanas que tem a sua obra poética toda editada, graças ao trabalho da Pallas, do Rio de Janeiro, que publicou, em 2011, Amargos como os frutos, reunião dos seis livros de poesia da autora, os quais cobrem o intervalo de mais de vinte anos de produção. É objeto de uma quantidade considerável de artigos, muitos dos quais incidem sobre as relações que a sua poesia permite estabelecer entre identidade e cultura, sublinhando-se o modo como se dá a figuração do elemento feminino; e de dissertações e teses, defendidas em diferentes universidades brasileiras, sob a orientação de algumas das mais renomadas pesquisadoras da área, no país.

A situação de Conceição Lima é um pouco diferente. Dos seus quatro livros de poemas, apenas o segundo, A dolorosa raiz do micondó, tem edição brasileira, sendo comparativamente mais discreta a sua fortuna crítica, embora estudiosas do porte de uma Laura Cavalcante Padilha ou de uma Carmen Lucia Tindó Sec- 
co tenham lhe dedicado belas e percucientes páginas. De se destacar, além de "No útero da ilha: o sonho e a vigília" (2007), de Secco, e "A memória e seu teatro de sombras na poesia de Conceição Lima" (2012), de Padilha, são os quatro artigos que a revista Mulemba já publicou sobre a poesia da autora, desde 2011; e, mais recentemente, a tese de Naduska Mário Palmeira, Um corpo que floresce: a poesia de Conceição Lima: casa, memória, identidades, defendida na Universidade Federal do Rio de Janeiro, em 2019.

Pode-se dizer, de qualquer maneira, que ambas as autoras são expoentes de manifestações poéticas de indubitável qualidade estética, confirmando o potencial inovador da poesia que vem de África, a sua contribuição para a expansão do universo de temas, posições e sensibilidades que conformam o âmbito do dito espaço lusófono, ${ }^{1}$ bem como para a problematização de algumas das hierarquias que ainda lhe são próprias. Dialogando com a tradição dos poetas que as precederam, seja em África, seja em outros lugares, Tavares e Lima têm obras que merecem o nosso cuidado, do qual procura se revestir o texto que segue.

\footnotetext{
1 Termo polêmico, parece-me sempre necessário lembrar sua dimensão neocolonial, ainda que se faça uso dele apenas para designar o heterogêneo espaço no mundo onde se produz literatura de língua portuguesa.
} 


\section{Paula Tavares}

Desde o livro de estreia, publicado dez anos após a independência de Angola, a poesia de Tavares provocava reações de entusiasmo em seus leitores, como aconteceu com Inocência Mata, que se mostrou atenta para a novidade trazida por tal poética. Afirmava a professora são-tomense, então, que estava a ver "pela primeira vez, na poesia africana, uma escrita em que a voz da mulher se fazia ouvir na sua individualidade, na sua feminilidade, na sua corporalidade" (MATA, 2011, p. 9). Nas palavras de Mata, ainda que fazendo uso dos "elementos da natureza e da sociocultura angolanas", já explorados pelos "consagrados" de gerações anteriores, Tavares conseguia inovar, em especial, no modo como realizava a "figuração simbólica do elemento feminino", a qual, até o momento, teria servido, sobretudo, para oferecer a imagem de uma "matriz do nacional, da concertação e da força comunitária vital" (MATA, 2011, p. 9).

A autora trazia mesmo significativas inovações em relação ao que haviam feito os ditos poetas "consagrados", não apenas em Angola, mas também em Moçambique, São Tomé e Príncipe ou Cabo Verde. Em Noémia de Sousa, decantada como a mãe dos poetas moçambicanos, por exemplo, o elemento feminino aparecia expressivamente associado ao significante África, o qual, por sua vez, não raro, associava-se à figura da mãe, fazendo-se bastante notável o desejo 
de retorno à "Mãe África” (SOUSA, 2016, p. 130), bem como a noção de que os africanos, embora de diferentes procedências, seriam todos irmãos. Não por acaso, algo parecido acontecia em poemas de José Craveirinha, no Agostinho Neto de Sagrada esperança ou em É nosso o solo sagrado da terra, da são-tomense Alda Espírito Santo, para citar apenas três dos "consagrados", cada um de uma nacionalidade diferente, mas todos muito ligados ao momento que ficou conhecido, na historiografia do espaço em questão, como o da poesia de combate.

Em Paula Tavares, entretanto, outros desdobramentos se tornavam visíveis, assumindo o elemento feminino dimensões menos conectadas à ideia de origem - étnica, racial ou nacional -, ao mesmo tempo em que menos associadas ao propósito de se fazer uma poesia voltada explicitamente contra as instituições do sistema colonial, antes claramente vistas como um inimigo a ser combatido, em nome da independência e da autonomia dos povos do continente. África, agora, não surgia mais como aquela grande nação que os antecessores da poeta pretendiam libertar, em sua visada marcadamente pan-africanista, preferindo-se abordar a questão do pertencimento por outros ângulos, não mais aqueles que dependiam da fundamental oposição entre colonizador e colonizado, a funcionar ideológica e poeticamente como base para a construção dos discursos a favor da emancipação nacional. 
Não se tratando mais da libertação nacional, todavia, é certo que anseios por libertação se faziam e fazem presentes, na poesia da autora, mobilizando-se a ideia da colonização como elemento com carga semântica ainda relevante, através de um certo deslocamento que muito diria a respeito da poética de Tavares e de sua afinação com questões de seu tempo. A apropriação e a ressignificação de um verbo como colonizar, tal como aparece em um dos poemas de Ritos de passagem, serão dignas de destaque, quanto a este ponto:

colonizámos a vida

plantando

cada um no mar do outro

as unhas da distância da palavra da loucura

enchendo de farpas a memória

preenchemos os dias de vazio

no alto destes muros

muito brancos

duas bandeiras velhas

a meia-haste

saúdam-se, solenes. (TAVARES, 2011, p. 61)

Fazendo-se uso de um procedimento recorrente, na obra - o deslocamento das palavras, no espaço da página, o qual já aponta para uma vontade de figuração do movimento -, observa-se uma espécie de mudança de escala da perspectiva com que se trata da ação colonizadora, a qual, agora, não envolveria mais grandes grupos antagônicos, como o seriam os euro- 
peus e os africanos. 0 poema remete a um passado em que a própria vida teria sido colonizada, focalizando-se dois sujeitos que parecem ter experimentado uma relação afetiva, senão amorosa, tornando-se evidentes as suas marcas. Tratando-se de uma ação recíproca, tem-se que ambos os sujeitos colonizam, sendo este o movimento que os afasta, distancia-os, deixando na memória "farpas" e a lembrança do "vazio" com que teriam sido preenchidos os dias. 0 que se planta, ação que se enfatiza no segundo verso, não é algo que une, que dá origem a mais vida, mas, antes, o que separa, estando a "palavra" - aquilo que poderia gerar compreensão e trocas entre os dois sujeitos - envolvida e como que emparedada pela "distância" e pela "loucura".

Se, em um primeiro momento, a voz que fala, no poema, coloca-se no plural, aludindo ainda à presença de uma conexão afetiva, na memória, na segunda estrofe desaparece a primeira pessoa, indicando-se somente o encontro frio de dois sujeitos, "duas bandeiras velhas", cuja ação é uma formal saudação, envolta em uma atmosfera de luto ("a meia-haste"), de perda de vitalidade. Com a referência aos "muros muito brancos", reforça-se mais a separação, aquela "distância" entre os dois sujeitos, pois que se insinua um certo excesso de branquidão (ou branquitude?), possível equivalente da ausência de misturas, sugerindo-se certas conotações raciais. Sendo tais misturas contrárias a um imaginável ideal de pureza, que 
poderia ser tanto cultural quanto étnica, a presença dos muros remete à incompreensão e à intolerância, marcas do sistema colonial, mas que o ultrapassam, perseverando, como acontece com os próprios ideais de elevação ("no alto destes muros"), os quais não podem deixar de carregar consigo a sua contrapartida, isto é, as ideias de rebaixamento e inferioridade.

Configurando-se a ausência do diálogo efetivo e afetivamente vivificador, que poderia levar à compreensão da diferença, bem como se sugerindo, por extensão de sentido, a imposição cultural e o virtual desejo de hierarquização de valores e cosmovisões, desenha-se, assim, a relação colonial. Diferentemente do que acontecia com a geração dos mencionados "consagrados", contudo, já não se manifesta, aqui, o indiciamento de um inimigo a ser combatido, de um invasor a ser expulso, em nome da preservação de uma identidade ameaçada. De acordo com essa nova perspectiva, a liberdade, dependente da ausência de muros e da manutenção da vitalidade dos sujeitos envolvidos na relação, resultaria da própria capacidade do indivíduo de evitar o fechamento em si mesmo, recusando-se o demasiado apego a certos padrões ou a sinais particulares de distinção, como o seriam as "duas bandeiras", "velhas" e "solenes".

A proposta do diálogo entre sujeitos, assim como entre culturas, em modo não-hierarquizado, aparece não apenas na poesia de Tavares, mas também em entrevistas e textos não literários seus, como naque- 
le em que associa o seu trabalho poético às ideias de devoração e canibalização, afirmando estar "aberta a todas as experiências do mundo", à "incorporação de vários patrimônios" (TAVARES, 2008, p. 49). ${ }^{2}$ Sua poesia, que acolhe elementos de culturas diversas, ocidentais e não-ocidentais, destacando-se uma variedade de registros de diferentes etnias africanas, seria, então, como a de Conceição Lima, nas palavras de Inocência Mata, tocada por uma espécie de "movimento de inclusão", cujo principal desígnio seria evitar a prevalência de olhares homogeneizantes, bem como todo e qualquer tipo de "monolitismo cultural" (MATA, 2010, p. 158).

\section{Conceição Lima}

A respeito de Lima, poeta que se inicia em livro já nos anos 2000 (O útero da casa é de 2004), Inocência Mata chega a identificá-la como uma "esteta do multiculturalismo" (MATA, 2010, p. 158), afirmando que o seu discurso poético estaria centrado "na utopia de uma sociedade inclusiva” (MATA, 2010, p. 165). Neste caso, embora se valorizando os ideais revolucionários associados às lutas pela independência e pela criação de uma nação livre, bem como os seus heróis, locais e continentais, tem-se também uma proposta que ul-

2 Diz a autora, em "Contar histórias": “[...] eu não faço cópias: trabalho, canibalizo e devoro como muitos outros africanos fizeram. [...] esse é realmente o trabalho que eu tento fazer, essa incorporação de vários patrimônios" (TAVARES, 2008, p. 49). 
trapassa dicotomias e essencializações, atentando-se paras as descontinuidades intrínsecas à história de comunidades nacionais internamente marcadas por diferenças e conflitos, os quais são colocados em evidência, ainda que se projete e se deseje a sua superação.

No segundo livro da autora, $A$ dolorosa raiz do micondó, ao lado de poemas em que se enfocam os estratagemas da colonização, como "Anti-epopeia", no qual se parece apresentar o momento de uma espécie de traição de um chefe de tribo, que levaria à dominação do próprio povo, surgem composições como "Zálima Gabon", em que são conflitos entre diferentes grupos da sociedade de São Tomé e Príncipe o que se destaca. A evidente ênfase na noção de pertencimento, que perpassa todo o livro, desde o seu título, não impede que se lance um olhar crítico para problemas internos, de modo a se impedir que uma visão ingênua e idealizada do lugar de origem aí se imiscua. Em "Anti-epopeia”, através de um registro paródico, a sublinhar o reverso do que seriam os grandes feitos de personagens heroicas, tem-se o seguinte:

Aquele que na rotação dos astros e no oráculo dos sábios buscou de sua lei e mandamento a razão, a anuência, o fundamento

Aquele que dos vivos a lança e o destino detinha Aquele cujo trono dos mortos provinha 
Aquele a quem a voz da tribo ungiu chamou rei, de poderes investiu

Por panos, por espelhos, por missangas

por ganância, avidez, bugigangas

as portas da corte abriu

de povo seu reino exauriu. (LIMA, 2012, p. 20)

Como se vê, a suposta grande figura humana do poema, referida apenas como "Aquele", um sujeito que em algum momento teria assumido o poder, na tribo, sendo uma sorte de escolhido para guiar o seu povo (por forças sobrenaturais, inclusive), é, aqui, devidamente responsabilizada. É ele quem teria cometido a ação de abrir as portas de sua corte, o que acabaria por levar ao esvaziamento do reino, ao seu completo esgotamento ("exauriu"), à sua morte. Motivada por sentimentos como a "ganância" e a cobiça, e se deixando enganar pelo outro, que a ela daria "panos", "espelhos", "missangas" e outras "bugigangas", em troca de favores não nomeados, a figura remete à história da colonização. Esta, porém, não se focaliza como se o objetivo fosse ressaltar o valor contrastante, em relação ao universo do colonizador, de uma possível "diferença cultural africana” (PADILHA, 2007, p. 453), a qual, embora a poesia de Lima reconheça, procurando afirmar a sua existência, não se imagina imune aos processos de reflexão e crítica. ${ }^{3}$

3 Uso a expressão "diferença cultural africana" no sentido que lhe dá Laura Cavalcante Padilha, em "Um trânsito por fronteiras", texto com o qual o meu tem grandes afinidades. 
0 ponto de vista adotado pelo poema, com efeito, não é o mesmo que se verificava com muita constância entre aqueles já referidos "consagrados", no momento da poesia de combate, em que uma antiepopeia, seguramente, seria uma epopeia com suas baterias voltadas contra o colonizador, isto é, hostil aos portugueses e seus supostos grandes feitos, elogiando-se, em contrapartida, a potência do guerreiro africano. É o que se faz, por exemplo, em poemas como "Xigubo", de José Craveirinha, em que se voltam a dançar as "danças do tempo da guerra / das velhas tribos juntas na margem do rio", com as "catanas ferozes" e a "azagaia rubra" (CRAVEIRINHA, 1980, p. 10) prontas a serem usadas contra o inimigo invasor. Agora, será o líder da própria tribo o grande responsabilizado, não interessando a sua nacionalidade, mas, antes, a natureza de sua ação, em relação ao seu povo, a qual diria muito sobre o seu caráter. É este, no que concerne à individualidade, mas, também, à exemplaridade, o que se deve condenar.

Que o chefe da tribo possa ser africano, entretanto, importa, deveras, tendo em vista o contexto em que a composição foi escrita, bastante diferente daquele que informava a poesia de Craveirinha ou de Agostinho Neto, quando se gestavam os movimentos que iriam levar às independências de Moçambique, Angola e dos demais países africanos de língua oficial portuguesa. Um par de poemas do livro de Lima, formado por "Os pequenos tiranos" e "Certos pequenos 
tiranos", bastante representativos da vertente engajada, politicamente interessada, dessa poesia, podem ser ilustrativos desse novo momento.

No primeiro dos textos, em que a figura do tirano é associada à do burocrata, como um homem de escritório marcado pelo medo e pelo distanciamento das massas, fala-se das "secretas linhas de acção", que circulam por "timbradas pastas"; fala-se dos "vazios conclaves", de sujeitos que "vivem barricados nos próprios passos"; fala-se do temor do "eco" e do "rasto" das "palavras": "[...] e sussurram o édito em minúsculos conclaves / porque temem das palavras o eco e o rasto" (LIMA, 2012, p. 45-46). No segundo, reforça-se o fechamento dos tiranos em seu universo pessoal e restrito, sendo eles figuras que se comovem com "o langor da linha na palma da própria mão", confundindo "amor" e "a vénia dos vassalos" (LIMA, 2012, p. 47). São corruptos, igualmente, os tiranos, aqueles que, não discernindo o que separa o público do privado, "publicam altos amigos como títulos de jornal / e distribuem grãos de favor como quem outorga um foral" (LIMA, 2012, p. 47).

Se, no primeiro dos dois poemas em questão, não se pode determinar com clareza o espaço em que vivem os tiranos, no segundo, a localização é precisa. Embora burocratas, "meticulosos no arrumar dos papéis", eles também "crêem no amparo de feitiços e amuletos" (LIMA, 2012, p. 47-48). Nascidos em África, "só por distracção morrerão em África" (LIMA, 
2012, p. 48). Na última estrofe da composição, fica evidente que essas figuras não são muito diferentes daquele sujeito de "Anti-epopeia", em particular, na sua relação com a própria pátria, em que sua ação, covardemente realizada, não é senão destrutiva: “Dói a doçura da savana espezinhada nesses pequenos tiranos / A pátria em seus ombros é divisa, cartão de visita / No borrão do carimbo dispara a AKA que nunca empunharam" (LIMA, 2012, p. 48).

Como se sabe, são muitos os problemas internos que a independência dos países africanos, de modo geral, não chegou a solucionar. Em Angola, a guerra civil, começada logo após a independência, durou mais de vinte anos (1975-2002); em Moçambique, durou quinze anos (1977-1992). Em São Tomé e Príncipe, apenas em 1990 foi instituído o pluripartidarismo. Em todos esses países, os índices de desenvolvimento humano são baixos, comparáveis aos das regiões mais pobres do Brasil. Interessada nas relações de poder, envolvendo diferentes classes e grupos, hierarquicamente dispostos, em um ambiente que contraria as utopias do passado, propulsoras da poesia de seus antecessores, tais problemas importam à poesia de Lima, a qual, evitando maniqueísmos e idealizações, seja com relação ao nacional, seja com relação ao que ultrapassa esse espaço, faz questão de colocar o dedo em certas feridas.

"Zálima Gabon", também de $A$ dolorosa raiz do micondó, é outro poema em que dissensões no âmbito 
de uma mesma nação - que, neste caso, evidencia-se claramente como sendo São Tomé e Príncipe - são realçadas. Mais uma vez, a perspectiva adotada não incide prioritariamente sobre a relação de conflito em que os antagonistas seriam o europeu e o africano, o colonizador e o colonizado, destacando-se, antes, o fenômeno da marginalização de um grupo específico, no contexto da sociedade são-tomense. Fala-se, no poema, em primeira pessoa, dos chamados "gabões", termo que vem a designar, pejorativamente, "serviçais idos do continente" (LIMA, 2012, p. 73) para São Tomé e Príncipe, remetendo originalmente a escravos levados do Gabão para as ilhas.

No texto, tais figuras aparecem como fantasmas, imagem que se apresenta já no título, uma vez que "zálima” quer dizer alma, espectro ou defunto. São estes "cadáveres sem cova”, que "arrastam a indignidade da sua vida e da sua morte", "com um peso de grilhões", nas palavras do poema, o que se deseja trazer à tona, recusando-se o seu apagamento, a sua inferiorização:

Falo destes mortos como da casa, o pôr do sol, o curso d'água.

São tangíveis com suas pupilas de cadáveres sem cova a patética sombra, seus ossos sem rumo e sem abrigo e uma longa, centenária, resignada fúria.

Por isso não os confundo com outros mortos.

Porque eles vêm e vão mas não partem Eles vêm e vão mas não morrem. 
Permanecem e passeiam com passos tristes que assombram o barro dos quintais

e arrastam a indignidade da sua vida e sua morte pelo ermo dos caminhos com um peso de grilhões. (LIMA, 2012, p. 22)

Em determinada altura do poema, em um movimento bastante significativo, a voz poética, que até então vinha falando de uma terceira pessoa ("eles"), dirige-se a um interlocutor, uma segunda pessoa do plural, a quem pede que não se feche ao "apelo" dos serviçais: "Não abafem o choro das crianças, não fujam / Não incensem as casas, não ocultem a face / Urgente é o apelo que arde por onde passam" (LIMA, 2012, p. 23). Fica evidente, em seguida, que este interlocutor, esta segunda pessoa, pertence a um grupo maior, o qual inclui o sujeito da enunciação, mas não os serviçais: "Por ambígua caridade, expiação de culpa / aos mortos-vivos ofertamos a mesa do candjumbi” (LIMA, 2012, p. 23). A oferta em questão é feita por um coletivo, um grupo, um "nós", que é movido por "remorso, temor, agreste memória" (LIMA, 2012, p. 23), por sentimentos ambíguos, entre os quais se inclui a culpa. Fazendo parte desse grupo, o sujeito poético, contudo, dele se distingue, constituindo-se como a voz que ecoa o apelo, sabendo ser necessário que aqueles fantasmas permaneçam ativos, na memória coletiva. Recusa-se "a tardia paz da sepultura, o olvido", de modo a que não se apague a "infâmia crua" 
de que são vítimas os gabões. Na penúltima estrofe do poema, fica bem indicada a posição adversa, resistente e não apaziguadora, dos mortos de que se fala:

Eles porém marcharão sempre, não dormirão Recusarão a tardia paz da sepultura, o olvido Acesa sua cólera antiga, seu grito fundo Ardente a aflição do silêncio, a infâmia crua. (LIMA, 2012, p. 23)

Ao fim e ao cabo, em se tratando dos gabões, que ainda hoje são vítima de preconceito, em São Tomé e Príncipe - em particular, por parte dos forros, grupo maioritário, na ilha de São Tomé -, realça a posição inclusiva da voz poética, a qual iria ao encontro do que Inocência Mata, pensando em termos de uma "identidade cultural da nação são-tomense" (MATA, 2010, p. 149), afirma ser a defesa de um pertencimento pela "nativização", em detrimento da postura mais restrita que se pautaria pela "vinculação a ancestralidades insulares" (MATA, 2010, p. 160). 0 gesto que se apresenta, estando ligado à própria concepção de Lima a respeito do que caberia ao poeta, como figura atenta e compromissada com os espaços por onde transita, seria o de fazer ecoar o "aviso" vindo das margens, não deixando que se esqueça, não permitindo que se oculte "a atormentada ternura" de um "sangue insepulto": 
Eis por que vigiam estes mortos a nossa praça seu é o aviso que ressoa no umbral da porta na folhagem percutem audíveis clamores

a atormentada ternura do sangue insepulto. (LIMA, 2012, p. 23)

\section{De volta a Paula Tavares}

Se poemas como "Zálima Gabon" ou “Jenin”, também de A dolorosa raiz do micondó, no qual se fala sobre uma batalha entre forças do exército israelense e civis e militantes palestinos, ${ }^{4}$ fazem jus à ideia de que a poética de Lima conduziria um projeto de "reconhecimento das subjetividades marginalizadas da história” (MATA, 2010, p. 150), é preciso que se diga que a de Paula Tavares não ficaria atrás, destacando-se, em especial, neste aspecto, o papel que em sua poesia assume a ligação com a terra, com o local e com o seu "legado" (TAVARES, 2008, p. 49).

O universo agrário - iluminado pelas "noites antigas de acender fogueiras" (TAVARES, 2011, p. 76), pela sabedoria das "mais velhas" (TAVARES, 2011, p. 80), que "desfiam uma lenta memória" (TAVARES, 2011, p. 77), onde pastam "os bois nascidos na huíla" (TAVARES, 2011, p. 45), região de origem da própria poeta, em Angola - seria, de fato, trazido à luz, na poesia de Tavares, em um movimento que daria forma ao

4 Em "Jenin", lê-se: "Os bulldozers partem sem fanfarras. / Arrastam na poeira as tiras das sandálias / e o pavor nas asas das galinhas" (LIMA, 2012, p. 50). 
desejo de reconhecimento de diferentes possibilidades de organização material e simbólica da vida, fruto de uma postura assentada naquilo que Boaventura de Sousa Santos chamaria de respeito à "diferença de concepções alternativas da dignidade humana" (SANTOS; NUNES, 2010, p. 25). Efetivamente, merece lugar de destaque, na poesia da autora, o mundo do campo, da camponesa ou do camponês, aquele "elemento [...] cuja estrutura social se mantém comunitária" e que defenderia "tenazmente as suas tradições" (FANON apud MATA, 2015, p. 26), como dizia já Frantz Fanon. Para Margarida Calafate Ribeiro, trata-se de uma poesia em que "outros sujeitos históricos e etno-culturais se revelam, mostrando [...] outras formas de estar e sentir o mundo, de viver a vida e de organizar a cultura, a memória e a história" (RIBEIRO, 2008, p. 123).

Havendo, aqui, uma manifesta vontade de valorizar certas tradições, notadamente marginalizadas, com ênfase no seu potencial de abrir espaço para lógicas alternativas, epistemologias e racionalidades outras, cabe reforçar, todavia, que tal universo não estará imune à possibilidade de se tornar objeto de reflexão crítica, não se tratando, portanto, de uma simples celebração da continuidade de um "mundo tradicional" (APPIAH, 1997, p. 179), que se desejaria ter permanecido estático, supondo-se o seu equilíbrio original, o qual se poderia imaginar ter sido "rompido pelo impacto do colonialismo" (COQUERY-VIDRO- 
VITCH apud APPIAH, 1997, p. 179). ${ }^{5}$ Naquele espaço, no qual a mulher, tão logo começa a menstruar, pode ser trocada por "bois, tecidos e enxadas" (TAVARES, 2011, p. 105), dando-se em casamento; um espaço no qual a mulher está condenada "a ser a outra / o vaso de forma estranha / aberto / fresco / preparado" (TAVARES, 2011, p. 86), também será preciso ter força para resistir, refletir e questionar, mantendo-se viva alguma "reserva de sonhos" (TAVARES, 2011, p. 73), como se diz no poema que abre o segundo livro de poesia da autora, $O$ lago da lua, do qual recorto a segunda estrofe:

\author{
No lago branco da lua \\ misturei meu sangue e barro branco \\ e fiz a caneca \\ onde bebo \\ a água amarga da minha sede sem fim \\ o mel dos dias claros \\ Neste lago deposito
}

5 São-me caras as reflexões de Kwame Anthony Appiah, em Na casa de meu pai: a África na filosofia da cultura. Para o autor, embora seja "verdade que existe uma diferença [...] na medida como a modernidade celebra a distância cognitiva em relação a [...] predecessores, enquanto o mundo tradicional celebra a continuidade" (APPIAH, 1997, p. 179), não se pode ter ilusões com relação a uma suposta estabilidade deste último. Para ilustrar o seu posicionamento, Appiah cita Catherine Coquery-Vidrovitch, de que aqui transcrevo mais algumas palavras: "Na verdade, essas sociedades supostamente estáveis raras vezes desfrutaram do encantador equilíbrio que se presume ter sido rompido pelo impacto do colonialismo. [...] Até onde teremos de recuar para encontrar a estabilidade tida como 'característica' do período pré-colonial: até antes da conquista portuguesa, antes da invasão islâmica, antes da expansão dos bantos?" (COQUERY-VIDROVITCH apud APPIAH, 1997, p. 179). 
minha reserva de sonhos

para tomar. (TAVARES, 2011, p. 73)

Construída a partir de uma propositada busca de ligação com a terra, com o local, de onde emanará um específico "olhar de ver o mundo" (TAVARES, 2008, p. 49), como diz a poeta, essa poesia não poderá recusar o movimento de abertura para os olhares vindos de outros mundos, constituintes da experiência de quem se reconhece como quem fala apenas "línguas imperiais" (TAVARES, 2008, p. 49). Será entre o próprio e o alheio, termos tornados reversíveis, em alguma medida, que se constituirá a contribuição de Tavares a um patrimônio cultural que se deseja não excludente, mas informado por amplas trocas e trânsitos. Como sugere o provérbio cuanhama que serve de epígrafe a $O$ lago da lua, a casa, aqui, não se apresenta como um lugar fixo, definitivo, ao qual retornar, ressaltando-se, antes, a necessidade e o gesto de construí-la: “... lá onde és amado constrói a tua casa" (TAVARES, 2011, p. 71).

\section{Conclusão}

Analogamente ao que se dá na obra de Conceição Lima, a poética de Paula Tavares, como se vê, revela-se informada pela noção de pertencimento a um lugar que se quer chamar de "casa", onde se poderá existir, nas palavras da voz poética de Lima, em "Inegável", 
"como a semente na fruta", como "o verso no poema" (LIMA, 2012, p. 54). ${ }^{6}$ Fundamental será notar, porém, que não se trata, em nenhum dos dois casos, de poéticas que se propõem a permanecer estanques, estacionadas em um único e definitivo lugar, recusando travessias, como se sua concepção de pertencimento pudesse dar origem a uma noção de identidade "rigidificada, sedimentada, mineralizada" (FANON, 2015, p. 244), lembrando termos de Frantz Fanon. ${ }^{7}$

Em ambas as poetas, patenteia-se o desejo de manter "o corpo aceso", de "saltar o cercado", como se lê em um poema sem título de Ritos de passagem. Neste, de modo expressivo, a interlocução se dá no sentido da recusa do lugar que o outro demarca para o sujeito poético, incidindo sobre a lógica patriarcal que estabelece posições de gênero fixas, e que não é privilégio do Ocidente, de África ou de outro espaço específico, mas transpõe tempos e espaços diversos. Começando com a constatação dessa lógica e desse

6 Eis "Inegável", na íntegra: "Por dote recebi-te à nascença / e conheço em minha voz a tua fala. / No teu âmago, como a semente na fruta / o verso no poema, existo. // Casa marinha, fonte não eleita! / A ti pertenço e chamo-te minha / como à mãe que não escolhi / e contudo amo." (LIMA, 2012, p. 54).

7 Diz Fanon: "Ao fim de um ou dois séculos de exploração colonial, dá-se uma autêntica emaciação do panorama cultural nacional. A cultura nacional torna-se um stock de hábitos motores, de tradições de vestuário, de instituições fragmentadas. Descobre-se aí pouca mobilidade. Não há criatividade autêntica, não há efervescência. [...] Após um século de dominação colonial, encontramos uma cultura extremamente rigidificada, sedimentada e mineralizada. A deterioração da realidade nacional e a agonia da cultura nacional mantêm relações de dependência recíproca." (FANON, 2015, p. 244). 
lugar ("Desossaste-me / cuidadosamente / inscrevendo-me / no teu universo / como uma ferida / uma prótese perfeita / maldita necessária") (TAVARES, 2011, p. 55), é isto o que se recusa, em direção a alguma espécie de liberdade:

Hoje levantei-me cedo

pintei de tacula e água fria

não bato a manteiga

o corpo aceso

não ponho o cinto

VOU

para o sul saltar o cercado. (TAVARES, 2011, p. 55)

É o movimento, em detrimento da estabilização, da fixidez, portanto, o que se vê, nessa poesia, como também na de Lima. É de um desejo de atravessamento, de contato com o outro, de inclusão da diferença, em termos não hierarquizantes, que se constituem as poéticas de ambas as autoras. Em Lima, embora se trate de plantar estacas "em redor da vigília" (LIMA, 2012, p. 70) dos seus mortos, como se diz em "Versão de deserto", último poema de $A$ dolorosa raiz do micondó, não se esquece o valor da "arte da viagem", definida como "aprendizagem de leme e remendo" (LIMA, 2011, p. 107), em “Circum-navegação", último poema de $O$ país de Akendenguê. Em Tavares, a par da presença dos ritos, das cerimônias, dos provérbios, do que seria próprio de sua terra, de que ela diz não se separar, destaca-se a recorrência da estrutura da 
interlocução, a partir da qual se pode notar um reforço da vontade de diálogo com o outro, o desejo de estabelecimento da relação que poderá alçar o sujeito a um outro plano, no movimento que o leve a sair de si, a evitar ser o que os "tiranos" de Conceição Lima ensinam que não se deve ser.

Estamos, então, diante de duas poetas que não se despregam de sua terra, que parecem desejar ir ao encontro de algum tipo de "substrato africano" (FERREIRA, 1975, p. 39), de que já falava Manuel Ferreira, identificando a sua presença em uma poesia como a de Noémia de Sousa, assim como identificava a presença de uma "consciência africana" (FERREIRA, 1975, p. 38), na obra da moçambicana e de muitos outros, dentre os quais os já citados Craveirinha, Alda Espírito Santo e Agostinho Neto. Sem dúvida, as poéticas de Tavares e Lima não pretendem virar as costas para o que pode ser próprio do lugar de onde querem fazer emanar as suas vozes, seja para os seus "hábitos, costumes, ritos" (FERREIRA, 1975, p. 39), seja para os problemas sociais, étnicos, de classe ou de gênero desses espaços, que são africanos, em sentido genérico, angolanos e são-tomenses, em termos mais específicos, cabindas, cuanhamas, forros ou angolares, em termos ainda mais específicos.

Em ambas, entretanto, é certo que tais universos não podem ser vistos como se de substâncias dotadas de identidades definitivas, unificadas e ameaçadas se tratasse, noção a partir da qual se justificaria uma ên- 
fase nacionalista na defesa contra inimigos externos ou um edênico desejo de retorno às origens. Em sua destacada abertura para o encontro com o outro, em cujo âmbito se vê a potência para a descoberta de um eu em construção permanente, ambas as poetas parecem mesmo demarcar a sua posição de diferença em relação aos chamados "consagrados", a quem importa reverenciar, dando continuidade ao seu legado, também no plano literário, mas abrindo novos caminhos, atravessando outros mares.

O tempo, agora, não precisa ser mais o do "monolitismo das ideologias nacionalistas" (MATA, 2015, p. 24), de que fala Inocência Mata (identificando a permanência de suas consequências, no presente), ou o da crença nas certezas que impulsionavam as utopias do passado, necessárias, naquele momento, respeitadas, ainda hoje, mas, sem dúvida, passíveis de ultrapassamento. Significativamente, são duas as ocorrências do verbo "trespassar", em O país de Akendenguê, ambas conectadas com a ideia da viagem. Em "Esta viagem", o sujeito poético diz: "Trespassei o aço das certezas. / Heranças, devorei-as." (LIMA, 2011, p. 71). Em "Fronteira", afirma-se: "Trespassar é a sina dos que amam o mar" (LIMA, 2011, p. 44). Para além das certezas - que poderiam dar por encerrada a travessia, a interrogação -, força é, pois, amar a vastidão desse mar, dos desafios, dos encontros, das dúvidas e descobertas que pode suscitar. 


\section{Referências}

AGOSTINHO NETO. Sagrada esperança. 10. ed. Rio Tinto: União dos Escritores Angolanos, 1988.

APPIAH, Kwame Anthony. Na casa de meu pai: a África na filosofia da cultura. Tradução de Vera Ribeiro. Rio de Janeiro: Contraponto, 1997.

BORDINI, Maria da Glória. Ilhas e continentes: uma poesia de limiares. Mulemba / UFRJ, Rio de Janeiro, v. 4, n. 7, p. 121-131, 2012. Disponível em: https://revistas.ufrj.br/index.php/mulemba/article/view/4957/16178. Acesso em: 22 set. 2020.

CRAVEIRINHA, José. Xigubo. 2. ed. Lisboa: Edições 70, 1980.

FANON, Frantz. Sobre a cultura nacional. In: FANON, Frantz. Os condenados da terra. Tradução de António Massano. 3. ed. Lisboa: Letra Livre, 2015, p. 209-253.

FELTRIN, Hector Rodrigues. Raízes do micondó de Conceição Lima: construções identitárias para além da estabilização. Mulemba / UFRJ, Rio de Janeiro, v. 11, n. 21, p. 184201, 2019. Disponível em: https://revistas.ufrj.br/index.

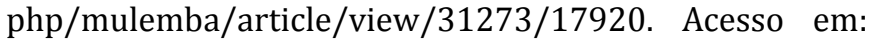
22 set. 2020.

FERREIRA, Manuel. Uma aventura desconhecida. In: FERREIRA, Manuel (org.). No reino de Caliban: antologia panorâmica da poesia africana de expressão portuguesa. Lisboa: Seara Nova, 1971, p. 16-63. v. 1 [Cabo Verde e Guiné-Bissau].

GONÇALVES, Guilherme de Souza Bezerra. Conceição Lima, para além do fim do mundo. Mulemba / UFRJ, Rio de Janeiro, v. 3, n. 4, p. 140-151, 2011. Disponível em: https://revistas. ufrj.br/index.php/mulemba/article/view/4872/16278. Acesso em: 22 set. 2020.

LIMA, Conceição. $O$ país de Akendenguê: poesia. Alfragide: Caminho, 2011. 
LIMA, Conceição. A dolorosa raiz do micondó: poesia. São Paulo: Geração Editorial, 2012.

MATA, Inocência. Desfiando memórias de além-mar: novas cartografias identitárias na literatura são-tomense. In: MATA, Inocência. Polifonias insulares: cultura e literatura de São Tomé e Príncipe. Lisboa: Colibri, 2010, p. 149-168. MATA, Inocência. Passagem para a diferença. In: TAVARES, Paula. Amargos como os frutos: poesia reunida. Rio de Janeiro: Pallas, 2011, p. 7-12.

MATA, Inocência. A pertinência de se ler Fanon, hoje. In: FANON, Frantz. Os condenados da terra. Tradução António Massano. 3. ed. Lisboa: Letra Livre, 2015, p. 5-33.

PADILHA, Laura Cavalcante. Um trânsito por fronteiras. In: LARANJEIRA, José Luís Pires et al. (orgs.). Estudos de literaturas africanas: cinco povos, cinco nações. Actas do Congresso Internacional de Literaturas Africanas de Língua Portuguesa. Lisboa: Novo Imbondeiro, 2007, p. 447-454. PADILHA, Laura Cavalcante. A memória e seu teatro de sombras na poesia de Conceição Lima. ContraCorrente: Revista de Estudos Literários, Manaus, v. 3, n. 3, p. 43-56. 2012.

PALMEIRA, Naduska Mário. Ilha e memória: uma leitura da obra $O$ útero da casa, de Conceição Lima. Mulemba / UFRJ, Rio de Janeiro, v. 8, n. 15, p. 136-144, 2016. Disponível em: https://revistas.ufrj.br/index.php/mulemba/article/ view/5339/16049. Acesso em: 22 set. 2020.

PALMEIRA, Naduska Mário. Um corpo que floresce: a poesia de Conceição Lima: casa, memórias, identidades. 160 p. Tese (Doutorado em Letras Vernáculas) - Faculdade de Letras, Universidade Federal do Rio de Janeiro. Rio de Janeiro, 2019. Disponível em: https://drive.google.com/file/ $\mathrm{d} / 1 \mathrm{p} 44 \mathrm{hm} 0$ ocjP0R0XKtsEkYuGBvfVvOIBbU/view. Acesso em: 22 set. 2020.

RIBEIRO, Margarida Calafate. E outras vozes se alevantam: Ana Paula Tavares responde a Luís de Camões. Ex Aequo, Vila Franca de Xira, n. 17, p. 119-129, 2008. 
SANTO, Alda Espírito. É nosso o solo sagrado da terra: poesia de protesto e luta. Lisboa: Ulmeiro, 1978.

SANTOS, Boaventura de Sousa; NUNES, João Arriscado. Introdução: para ampliar o cânone do reconhecimento, da diferença e da igualdade. In: SANTOS, Boaventura de Sousa (Org.). Reconhecer para libertar: os caminhos do cosmopolitismo multicultural. 2. ed. Rio de Janeiro: Civilização Brasileira, 2010, p. 25-68.

SECCO, Carmen Lucia Tindó Ribeiro. No útero da ilha: o sonho e a vigília. In: TUTIKIAN, Jane; ASSIS BRASIL, Luiz Antonio de (Org.). Mar horizonte: literaturas insulares lusófonas. Porto Alegre: EDIPUCRS, 2007, p. 135-152.

SOUSA, Noémia de. Sangue negro. São Paulo: Kapulana, 2016.

TAVARES, Paula. Contar histórias. In: PADILHA, Laura Cavalcante; RIBEIRO, Margarida Calafate (Orgs.). Lendo Angola. Porto: Afrontamento, 2008, p. 39-50.

TAVARES, Paula. Amargos como os frutos: poesia reunida. Rio de Janeiro: Pallas, 2011. 